\title{
A Novel Optimization Approach Applied in Injection Molding of a Led Lighting Module
}

\author{
Wen-Chin Chen, Po-Yao Chang, and Yi-Chia Tai
}

\begin{abstract}
This study presents a novel optimization approach for injection molding with multiple performance characteristics through data mining and analysis to effectively determine the optimal process parameter settings. The quality characteristics of the LED lighting modulus can be categorized into the beam angle and the luminous intensity. The control factors for the process are mold temperature, melt temperature, injection velocity, packing pressure and VP switch. The Taguchi method is employed to conduct signal-to-noise $(\mathrm{S} / \mathrm{N})$ ratio optimization. Taguchi orthogonal array experiments are performed, and then the experimental data are trained and tested by back-propagation neural networks to create a $S / N$ ratio predictor. In addition, the $S / N$ ratio predictor is combined with genetic algorithms (GA) to obtain the process parameter combination on maximum $\mathrm{S} / \mathrm{N}$ ratio for both beam angle and luminous intensity. As a result, the proposed novel optimization approach can create the better process parameter settings which can not only be more robust and meet the dimension specification, but also enhance the stability of injection process.
\end{abstract}

Index Terms - LED lighting modulus, injection molding, Taguchi orthogonal array, BPNN, GA.

\section{INTRODUCTION}

Due to the increasingly advanced manufacturing technology in recent years, costs continue to drop consequently, causing LED industries to face with increasingly intense competition. Nonetheless, as the dimension of future application broadens and demand increases, it is inevitable that more traditional lighting sources of lighting will be replaced. LED lighting module has gradually used optical plastic material and produces through injection molding process, progressing towards the development trend with high precision. In general, the optical functions of optical plastic materials are often reduced due to poor mold design or inappropriate molding parameters during injection molding, molding defects such as residual stress and changes in the surface profile curvature. With regards to molding parameters, the majority of engineers used to rely on their experiences and intuitive for the configuration of optical design and injection molding process parameters. The process parameter combinations are determined after conducting multiple times of trial-and-error or experiment designs, which often consumes immerse time and costs and thereby affecting the quality of injection molding products. Due to the high nonlinear relationship between parameters, the process parameter combination found is rarely the optimal combination. A large number of

Manuscript received October 15, 2013; revised December 25, 2013.

Wen-Chin Chen, Po-Yao Chang, and Yi-Chia Tai are with the Department of Industrial Management, Chung-Hua University, Taiwan (e-mail: wenchin@chu.edu.tw, m10121019@chu.edu.tw, tai.yichia@msa.hinet.net). scholars in the past have adopted Taguchi Method to discuss the process parameter configuration for the plastic injection molding in various industries [1]-[5]. Nonetheless, the employment of Taguchi method could not find out the optimal process parameter since it only looks for the process parameters with discrete combination. The use of inappropriate process parameter combination will lead to the generation of product defects and process instability. To solve these issues, many scholar have applied optical simulation software such as Moldex3D, Moldflow, and C-MOLD, to conduct experiments with injection forming simulation and carry out the novel optimization research through the combination of GA or PSO algorithms [6]-[10]. Nevertheless, the simulation software somewhat varies from the actual injection due to the negligence on the internal and external noise interference control factors. Hence, many scholars collects data from the actual injection experiment to solve the aforementioned problems, using neural networks combined with some optimization methods such as Genetic Algorithm (GA) and Particle Swarm Optimization (PSO) as well as other optimization methods to conduct search for the optimal parameter design. The learning ability of neural network can accurately predict the outcome when faced with complex and nonlinear problems. Chen et al. [11] analyzes the optimization of process parameter for plastic injection by building the quality predictor on the data obtained from Taguchi Experiment through back-propagation neural networks, which is combined with Genetic Algorithm for the optimization of process parameters in plastic injection molding. When the experiment shows that the scope of limited process parameter falls on the optimal $\mathrm{S} / \mathrm{N}$ ratio $\pm 1 / 2$ Taguchi experiment standards, the solution sought by Genetic Algorithm outperforms the process parameter combination found out by the Taguchi experiment plan. Tzeng et al. [12] proposed a study on the process parameter optimization that combines Taguchi method, Response Surface Methodology, Genetic Algorithm, and Back-Propagation Neural Network to analyze the mechanical changes in the injection molding technology for polycarbonate composite material mixed of short fiberglass and enhanced polytetrafluoroethylene fiber. However, the aforementioned research only takes into consideration of product quality without analyzing the process stability.

Hence, the study proposes a set of LED lighting module injection molding process optimization to avoid the occurrence of product stress and impact on optical quality due to the errors in process parameter configuration. This model first carries out $\mathrm{S} / \mathrm{N}$ ratio optimization, conducting the injection molding experiment on the lighting module according to the Taguchi orthogonal array $\left(\mathrm{L}_{25} 5^{6}\right)$ to calculate the $\mathrm{S} / \mathrm{N}$ ratio based on the experiment data. The back-propagation neural network is used to build the $\mathrm{S} / \mathrm{N}$ ratio predictor and conduct global search through $\mathrm{S} / \mathrm{N}$ ratio 
predictor combined with genetic algorithm (GA), finding the optimal process parameter combination and maximizing the $\mathrm{S} / \mathrm{N}$ ratios of all quality characteristics. The experiment outcome proves that the model proposed by the study not only conforms product quality to standards but also lower the variance produced at process.

\section{PROPOSED APPROACH}

The study proposes a novel optimization approach for the injection molding process of LED lighting module, searching for a set of process parameter combination that can concurrently meet quality characteristics with beam angle of $18^{\circ}$ and maximum luminous intensity through conducting the research on parameter optimization for injection molding process of multiple quality characteristics. The process parameters include mold temperature, melt temperature, injection velocity, packing pressure, and VP switch. The actual injection molding experiment is conducted according to the Taguchi Orthogonal Array $\left(\mathrm{L}_{25} 5^{6}\right)$, whereas each parameter combination injects for 3 times before conducting optical testing based on the parameter combination obtained from the Taguchi experiment. The $\mathrm{S} / \mathrm{N}$ ratio is calculated from the experiment data, followed by building the $\mathrm{S} / \mathrm{N}$ ratio predictor $\left(\mathrm{BPNN}_{\mathrm{SN}}\right)$ through back-propagation neural network. Then, the $\mathrm{BPNN}_{\mathrm{SN}}$ predictor is combined with Genetic Algorithm to carry out global search and to find out the optimal process parameter combination. Finally, the actual injection molding experiment verifies the novel process parameter optimization model proposed by the study.

\section{A. Experimental Equipments}

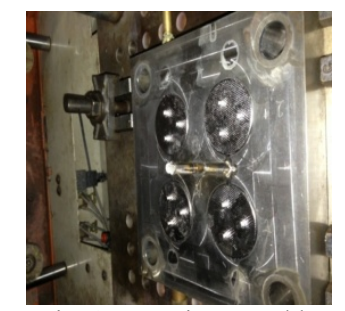

Fig. 1. Experimentmold.

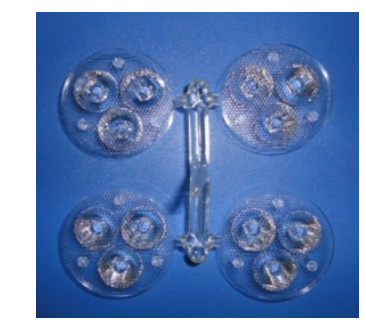

Fig. 2. Injection molding products.

The Victor Taichung Vs-80 injection molding machine and VICTOR-8000C controller are used as the experiment machines. The plastic material used for injection molding is optical-grade PMMA. The experiment mold employed in this study is a general two-plate mold with dimension in $300 \mathrm{~mm}$ of length, $300 \mathrm{~mm}$ in width, and $300 \mathrm{~mm}$ in height. The design of water channel adopts 2 inbound and outbound cavities on the core and the taper, forming one mold with 4 cavities. With the exception of employing pre-hardened steel NAK80 material for the core and the taper, the remaining mold materials adopt PDS5 materials. Fig. 1 shows the experiment mold and the lens products after injection molding, as shown in Fig. 2.

\section{B. Implementation of Taguchi Method and ANOVA}

TABLE I: LIST OF PARAMETERS

\begin{tabular}{lccccc}
\hline \multicolumn{6}{c}{ TABLE I: LIST OF PARAMETERS } \\
$\begin{array}{lccccc}\text { Mold } \\
\text { temperature }\end{array}$ & $\begin{array}{c}\text { Melt } \\
\text { temperature }\end{array}$ & $\begin{array}{c}\text { Injection } \\
\text { velocity }\end{array}$ & $\begin{array}{c}\text { Packing } \\
\text { pressure }\end{array}$ & $\begin{array}{c}\text { VP } \\
\text { switch }\end{array}$ \\
\hline Leve1 & 65 & 220 & 20 & 36 & 10 \\
\hline Leve2 & 71.25 & 225 & 22.25 & 41 & 11.25 \\
\hline Leve3 & 77.5 & 230 & 24.5 & 46 & 12.5 \\
\hline Leve4 & 83.75 & 235 & 26.75 & 51 & 13.75 \\
\hline Leve5 & 90 & 240 & 30 & 56 & 15 \\
\hline
\end{tabular}

TABLE II: ANOVA OF QUALITY CHARACTERISTICS (BEAM ANGLE)

\begin{tabular}{ccccccc}
\hline Source & DF & Seq SS & Adj SS & Adj MS & F & P \\
\hline Mold temperature & 4 & 22.1929 & 22.1929 & 5.5482 & 287.4 & 0.000 \\
\hline Melt temperature & 4 & 0.7842 & 0.7842 & 0.1961 & 10.16 & 0.023 \\
\hline Injection velocity & 4 & 1.7025 & 1.7025 & 0.4256 & 22.05 & 0.005 \\
\hline Packing pressure & 4 & 2.0094 & 2.0094 & 0.5023 & 26.02 & 0.004 \\
\hline VP switch & 4 & 0.3566 & 0.3566 & 0.0891 & 4.62 & 0.084 \\
\hline Error & 4 & 0.0772 & 0.0772 & 0.0193 & & \\
\hline Total & 24 & 27.1228 & \multicolumn{7}{c}{ R-Sq $=99.72 \%$} & R-Sq(adj) $=98.29 \%$ \\
\hline
\end{tabular}

TABLE III: ANOVA OF QUALITY CHARACTERISTICS (LUMINOUS INTENSITY)

\begin{tabular}{ccccccc}
\hline Source & DF & Seq SS & Adj SS & Adj MS & F & P \\
\hline Mold temperature & 4 & 4.70117 & 4.70117 & 1.17529 & 346.83 & 0.000 \\
\hline Melt temperature & 4 & 0.16912 & 0.16912 & 0.04228 & 12.48 & 0.016 \\
\hline Injection velocity & 4 & 0.35733 & 0.35733 & 0.08933 & 26.36 & 0.004 \\
\hline Packing pressure & 4 & 0.44477 & 0.44477 & 0.11119 & 32.81 & 0.003 \\
\hline VP switch & 4 & 0.07200 & 0.07200 & 0.01800 & 5.31 & 0.067 \\
\hline Error & 4 & 0.01355 & 0.01355 & 0.00339 & & \\
\hline Total & 24 & 5.75795 & & & & \\
\hline & \multicolumn{7}{c}{$\mathrm{R}-\mathrm{Sq}=99.76 \%$} & $\mathrm{R}-\mathrm{Sq}(\mathrm{adj})=98.59 \%$ \\
\hline
\end{tabular}

TABLE IV: PARAMETER COMBINATION OF THE S/N RATIO BETWEEN BEAM ANGLE AND MAXIMUM LUMINOUS INTENSITY

\begin{tabular}{cccccc}
\hline \multicolumn{6}{c}{ ANGLE AND MAXIMUM LUMINOUS INTENSITY } \\
\hline Response & $\begin{array}{c}\text { Mold } \\
\text { temperature }\end{array}$ & $\begin{array}{c}\text { Melt } \\
\text { temperature }\end{array}$ & $\begin{array}{c}\text { Injection } \\
\text { velocity }\end{array}$ & $\begin{array}{c}\text { Packing } \\
\text { pressure }\end{array}$ & $\begin{array}{c}\text { VP } \\
\text { switch }\end{array}$ \\
\hline beam angle & 83.8 & 235 & 22 & 56 & 12.5 \\
\hline luminous & 77.5 & 220 & 25 & 56 & 11.3 \\
\hline $\begin{array}{c}\text { Taguchi } \\
\text { method }\end{array}$ & 80.7 & 235 & 24 & 56 & 11.9 \\
\hline
\end{tabular}

This section conducts experiment and analysis on the LED lighting module injection molding process. The study first evenly distributes the control factors and configuration range values into 5 levels, whereas the range of factor levels include (mold temperature) $65-90^{\circ} \mathrm{C}$, (melt temperature) $220-240^{\circ} \mathrm{C}$, (injection velocity) $20-30 \mathrm{~mm} / \mathrm{se}$, (packing pressure) $36-56$ $\mathrm{MPa}$, and (VP switch) $10-15 \mathrm{~mm}$. The experiment adopts $\mathrm{L}_{25}\left(5^{6}\right)$ orthogonalarray, and design parameters are shown in Table I. In addition, No. 1-No. 25 consist of Taguchi 
experiment data and No. 26-No. 30 consists of testing data are randomly generated within the Taguchi range. Three replications are used for each setting to increase the sensitivity of statistical analysis, yielding 90 injection date. The optimal Taguchi combination of the beam angle and luminous intensity obtained from the value and $\mathrm{S} / \mathrm{N}$ ratio calculated through $\mathrm{L}_{25}\left(5^{6}\right)$ Taguchi orthogonal array experiment are Combination 19 (58.88) and Combination 11 (63.66). In particular, the adoption of $\mathrm{S} / \mathrm{N}$ calculation for quality characteristics needs to take consideration of the nominal the best and the larger the better in the variance and standard deviation of quality characteristics concurrently. Next, the data obtained from the experiment undergo ANOVA analysis for the beam angle and luminous intensity to find out the significant factors with significant impact on the beam angle and luminous intensity, followed by selecting the optimal Taguchi parameter combination through the significance. Using P-value smaller than 0.05 as the threshold, ANOVA shows that mold temperature, melt temperature, injection velocity, and packing pressure have more significant impact on the beam angle of quality characteristics. In contrast, mold temperature and injection velocity have more significant impact on the luminous intensity of quality characteristics. See the Table II and Table III. According to the significance in the factors between the quality characteristics from the results of the above analysis, both quality characteristics with significant and insignificant factors adopt the average value as the optimal Taguchi factor level. For one of the quality with significant and insignificant factor, the level of significance is taken as the optimal factor, as shown in Table IV.

\section{Optimization Model}

The study employs MATLAB for program design, using back-propagation neural network to build $\mathrm{S} / \mathrm{N}$ ratio predictor $\left(B P N N_{S / N}\right)$. The experiment data obtained from Taguchi orthogonal array $\mathrm{L}_{25}\left(5^{6}\right)$ are used for BPNN training and testing data, using five control factors, including the mold temperature (A), melt temperature (B), injection velocity (C), packing pressure (D), and VP switch (E), as the input for $\mathrm{BPNN}$. The quality characteristics include the $\mathrm{S} / \mathrm{N}$ ratio of the beam angle and luminous intensity, which serves as the BPNN output and undergoes 1549 generations of training to yield the BPNN training and RMSE as 0.0032 and 0.0508 . Next, the genetic algorithm and $\mathrm{S} / \mathrm{N}$ ratio predictor $\left(\mathrm{BPNN}_{\mathrm{S} / \mathrm{N}}\right)$ are combined and undergo LED lighting module injection molding process parameter optimization, using genetic algorithm to conduct global search on Taguchi parameters, whereas the parameters search are configured to the range between the upper and lower limit of various Taguchi parameters, the size of crossover is 100 , the crossover method uses one-point crossover, and the crossover rate is 0.8 . The mutation method applies one-point mutation with mutation rate of 0.6 , yielding convergence threshold of $1.0000 \mathrm{e}-005$ or iteration of 30000 generations. The Fitness Function of genetic algorithm is shown below:

$$
\begin{aligned}
& \operatorname{Min} f(x)=\left(S N_{O 1}-58.88\right)^{2}+\left(S N_{O 2}-63.66\right)^{2} \\
& \text { s.t. } \\
& \qquad 65 \leq A \leq 90,220 \leq B \leq 240,20 \leq C \leq 30 \\
& 36 \leq D \leq 56,10 \leq E \leq 15
\end{aligned}
$$

where $S N_{O i}$ is the $\mathrm{S} / \mathrm{N}$ ratio predicted by $\mathrm{BPNN}_{\mathrm{S} / \mathrm{N}}$ for the beam angle; is the $\mathrm{S} / \mathrm{N}$ ratio predicted by for the luminous intensity. 58.88 is the target value for $\mathrm{S} / \mathrm{N}$ ratio of the beam angle in quality characteristics and 63.66 is the target value for $\mathrm{S} / \mathrm{N}$ ratio of the luminous intensity in quality characteristics.

\section{RESULTS AND DISCUSSION}

After numerical analysis, the optimal parameters are $\mathrm{A}$ $($ mold temperature $)=82.9^{\circ} \mathrm{C}, \mathrm{B}($ melt temperature $)=239 .{ }^{\circ} \mathrm{C}$, $\mathrm{C}($ injection velocity $)=20.6 \mathrm{~mm} / \mathrm{sec}, \mathrm{D}$ (packing pressure $)=$ $51.6 \mathrm{MPa}$, and $\mathrm{E}$ (VP switch) $=14.5 \mathrm{~mm}$. In addition, the study conducts confirmation experiment on the optimal parameter combination obtained from the Taguchi Method and the proposed optimization approach. Fifteen measurements and calculation conducted in actual experimentare organized in Table V and Table VI. In terms of the luminous intensity of quality characteristics, the luminous intensity undergone the process optimization of this model is significantly better than the Taguchi method, whereas the average value of luminousintensity increases from $1335.24 \mathrm{~cd}$ to $1435.28 \mathrm{~cd}$ while the standard deviation also drops from 87.83 to 26.28 . In terms of the beam angle of quality characteristics, the average beam angle of $17.87^{\circ}$ approaches more to the target value of $18^{\circ}$, compared with the average beam angle of $18.25^{\circ}$ obtained from the Taguchi method. The standard deviation drops from 0.38 to 0.17 , implying that not only is the beam angle approaching to the target value, the luminous intensity enhances and the process becomes more stabilized having undergone the model process optimization. Process Capacity Index $\left(C_{p k}\right)$ is an important index for evaluating process stability. The minimum $C_{p k}$ threshold in LED lighting module injection molding process is 1.33 and any value smaller than 1.33 will prevent effective output and possibly produce more defects. The $C_{p k}$ value of the Taguchi method is 0.665 . After the novel optimization process, the $C_{p k}$ value increases to 1.729 . This reveals that not only the product quality approaches the target value but the process becomes more stabilized at the same time, after undergoing the novel optimization.

TABLE V: COMPARATIVE ANALYSIS OF OPTIMIZATION RESUlT (BEAM

\begin{tabular}{cll}
\multicolumn{3}{c}{ ANGLE) } \\
\hline Beam angle & AVERAGE & Standard Deviation \\
\hline $\begin{array}{c}\text { Taguchi's } \\
\text { method }\end{array}$ & 1335.24 & 87.83 \\
\hline $\begin{array}{c}\text { Proposed } \\
\text { Approach }\end{array}$ & 1435.28 & 26.28 \\
\hline
\end{tabular}

TABLE VI: COMPARATIVE ANALYSIS OF OPTIMIZATION (LUMINOUS INTENSITY)

\begin{tabular}{cccc}
\hline Luminous & Cpk & AVERAGE & Standard Deviation \\
\hline Taguchi's method & 0.665 & 18.25 & 0.38 \\
\hline Proposed Approach & 1.729 & 17.87 & 0.17 \\
\hline
\end{tabular}

\section{CONCLUSION}

The proposed approach can effectively solve the flaw in the Taguchi method, which yields the global optimum while utilizing genetic algorithm to break away from local optimum. 
The experimental results support the proposed approach which not only enhances the stability of the entire LED lighting module injection molding process but also improve quality characteristics, the beam angle and luminous intensity. There, the proposed novel optimization approach can create the better process parameter settings which can not only be more robust and meet the dimension specification, but also promote the stability of injection process.

\section{ACKNOWLEDGEMENT}

This research was supported by a grant (NSC 101-2221-E-216 -015) from the National Science Council, Taiwan.

\section{REFERENCES}

[1] M. Altan, "Reducing shrinkage in injection moldings via the Taguchi ANOVA and neural network method," Mater Des, vol. 31, pp. 599-640, 2010.

[2] W. C. Chen, G. L. Fu, P. H. Tai, and W. J. Deng, "Process parameter optimization for MIMO plastic injection molding via soft computing," Expert Systems with Applications, vol. 36, no. 2, pp. 1114-1122, 2009.

[3] C. H. Wu and W. S. Chen, "Injection molding and injection compression molding of three-beam grating of DVD pickup lens," Sensors \& Actuators: A. Physical, vol. 125, no. 2, pp. 367-375, 2006.

[4] W. J. Deng, C. T. Chen, C. H. Sun, W. C. Chen, and C. P. Chen, "An effective approach for process parameter optimization in injection molding of plastic housing components," Polymer-Plastics Technology and Engineering, vol. 47, no. 9, pp. 910-919, 2008.

[5] M. C. Song, Z. Liu, M. J. Wang, T. M. Yu, and D. Y. Zhao, "Research on effects of injection process parameters on the molding process for ultra-tjin wall plastic parts," Journal of Materials Processing Technology, vol. 187-188, pp. 668-671, 2007.

[6] C. C. Chen and C. S. Kuo, "Study on volumetric shrinkage for injeciton molding of optical homogenize," presented at 2010 Conference on Society of Manufacturing Engineers-SME 2010, 2010.

[7] W. C. Chen, T. T. Lai, and M. W. Wang, "An optimization system for LED lens design," Expert Systems with Applications, vol. 38, pp. 11976-11983, 2011.

[8] W. C. Chen, K. P. Liu, B. G. Liu, and T. T. Lai, "Optimization of optical design for developing an LED lens module," Neural Computing \& Applications, vol. 22, pp. 881-823, 2012.

[9] W. S. Chen, F. J. Yu, and S. H. Wu, "A robust design for plastic injection molding applying Taguchi method and PCA," Journal of Science and Engineering Technology, vol. 7, no. 2, pp. 1-8, 2011.
[10] W. C. Chen, L. Y. Wang, C. C. Huang, and T. T. Lai, "Parameter optimization of the injection molding process for a LED lighting lens using soft computing," Advanced Materials Research, vol. 690-693, pp. 2344-2351, 2013.

[11] W. C. Chen, M. W. Wang, C. T. Chen, and G. L. Fu, “An integrated parameter optimization system for MISO plastic injection molding," International Journal of Advanced Manufacturing Technology, vol. 44, pp. 501-511, 2009.

[12] C. J. Tzeng, K. Y. Yang, Y. H. Lin, and C. H. Tsai, "A study of optimization of injection molding process parameters for SGF and PTFE reinforced PC composites using neural network and response surface methodology," The International Journal of Advanced Manufacturing Technology, vol. 63, pp. 691-704, 2012.

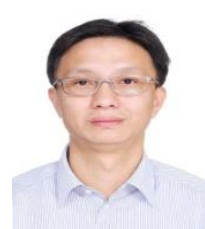

Wen-Chin Chen received the Ph.D. degree in mechanical engineering from University of Florida, USA, in 1995. He is a professor of industrial management at Chung-Hua University, Hsinchu, Taiwan. He has published papers in Neural Computing and Applications, International Journal of Advanced Manufacturing Technology, Mathematical Problems in Engineering, Expert Systems with Applications, Technovation, Applied Economics Letters, International Journal of Heat and Mass Transfer, and Journal of Heat Transfer, ASME. His research areas include Optimization Control in Engineering, Advanced Process control, Automation, and Performance Assessment.

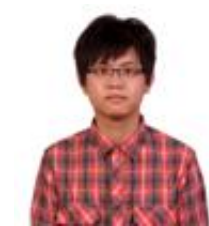

Po-Yao Chang received the bachelor degree in industrial management on June, 2012. Nowadays, He enrolled in the M.S. program, and his undergraduate and graduate programs are both at Chung-Hua University in Taiwan. During the graduate school period, he is a research assistant. His research fields are Engineering Optimization and Quality Management. In addition, he is a student member of the Chinese Institute of Industrial Engineers.

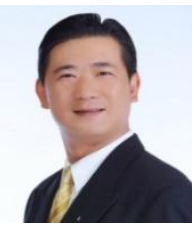

Yi-Chia Tai was born on 14 November 1964 in Taoyuan County, Taiwan. He received his Ph.D. program of technology management at the Chung Hua University in July 2013. He is a general manager of Kou-Shin Aluminum Industrial Company. The company manufactures aluminum doors \& windows for construction companies. He also lectures on Risk Management and Industrial Marketing at the Chung-Hua University. Dr. Tai has published "Parameter optimization of etching process for a LGP stamper" in the Neural Computing \&Applications, DOI 10.1007/s00521-012-1103-2 and "A Research of a Remote Control System Based on Timed Petri Net for PDA" in the Advanced Materials Research, 472-475, pp. 1114-1118. 